\title{
Cybersquatting: Threat to Domain Name
}

\author{
Sukrut Deo, Sapna Deo
}

\begin{abstract}
The present article deals with conflicts arising out of registration of domain names of existing trade names with the intention to resell it and/or encash the goodwill. Such practice is known as 'Cybersquatting'. Registration of Domain names and acquiring a domain name of choice has become a rage over the time. It is the first come first get thing for getting registered. In this paper the researcher has explained what a cybersqatting is alongwith various types of cybersquatting and its prevention and targets. This paper also suggests remedial measures to deal with cybersquatting. The Anti Cybersquatting Consumer Protection Act (ACPA), an enactment by United States, needs a special applaud for being the first country to have introduced a special act for dealing with the menace of cybersquatting which was the need of the hour. It so happens that people opt to buy the domain name from squatters as it being cheap instead of seeking remedy from the court of law.
\end{abstract}

Keywords- Domain name, Cybersquatting, Registrants, Typosqatting, Passing off

\section{INTODUCTION}

Recent trend of internet has brought up revolution in the business world. Many business groups have taken it to the online trade of marketing and business which gives a bigger exposure to their businesses. This has attracted an unhealthy competition where people try to misuse existing trade names of other proprietors for their benefit with an intention to encash the goodwill associated with such trade name painstakingly created by the proprietor.

All the reputed trade mark owners may not have or don't have their domain, which may be cashed by the competitive firm. It's a first come first thing as far as registering a domain name is concern. The person who gets the name similar to that of a trade name and tries to sell or shell money out of it commits Cybersquatting. The challenge that the law has faced in recent years is how to foster the development of intellectual property on the internet while preventing its unauthorized exploitation. [1]

The practice of cybersqatting came into existence with the advent of rise of domain names. Not all the traders are net or technology savvy this means that their trade name can be get used by some other trader, in turn he may try to sell it to the real owner of the trademark such domain name. In this paper the researcher has used doctrinal method to collect data to find out various studies and findings pertaining to Cybersqatting. Also the remedial measures that are available and its efficacy are studied.

Usually to register any domain names the cybersquatters are free to do so even if a domain name similar to such domain name already exists. For generating profits usually

\footnotetext{
Revised Manuscript Received on April 12, 2019.

Sukrut Deo, Assistant Professor, Bharati Vidyapeeth (Deemed to be) University,NEW Law College, Pune.India.(E-mail: ukrutdeo29@gmail.com)

Dr.Sapna Deo, Assistant Professor, Bharati Vidyapeeth (Deemed to be)University, NEW Law College, Pune .India(E-mail:
} apna.deo@nlc.bvdu.in) cybersquatters use combination of illicit and legal work. The end results in the legitimate owner suffering a huge loss.

\section{METHODOLOGY}

The methodology opted by the researcher is "doctrinal". Such Doctrinal legal research has been carried out through following sources such as International Treaties, Covenants and Conventions; Constitutional Provisions; Information Technology Act, 2000; Trademarks Act, 1999; Copyrights Act, 1957; ICANN, WIPO, UNDRP etc.; Reported decisions of the courts and Secondary Sources such as Commentaries and reference books; Journals; Magazines; Newspaper articles; Official Statistics; Internet sources.

\section{FINDINGS}

Cybersquatting is the phenomenon which is associated with the registration of domain names on the internet. It is the crime against property of an individual or a company/firm/trade. It is one of the most crucial act of concern to the world today.

In the Anti Cybersquatting Consumer Protection Act (ACPA) of the United States cybersquatting defines as the: "registration, trafficking in or using of a domain name that is identical or confusingly similar to a trademark, a service mark of another that is famous mark at the time of the registration of the domain name, without regard to the goods or services of the parties, with the bad faith intent to profit from the goodwill of another's mark which:

(a) results in consumer fraud and public confusion as to the true source of sponsorship of goods and services;

(b) impairs electronic commerce, which is important to interstate commerce and the United States economy;

(c) deprives legitimate trademark owners of substantial revenues and consumer goodwill; and

(d) places unreasonable, intolerable, and overwhelming burdens on trademarks owner in protecting their valuable trademarks."

Under WIPO, cybersquatting is -

The domain is identical or misleadingly similar to trade or service mark in which the complainant has a right;

The holder of the domain name has no right or legitimate interest in respect of the domain name; and

The domain name has been registered and is used in bad faith.

In Manish Vij v. Indra Chugh[2] the court has held: “ an act of obtaining fraudulent registration with an intent to sell the domain name to the lawful owner of the name at a premium." Obtaining fraudulent registration with intent to sell the domain name to the lawful owner of the name at premium is called "cybersquatting"[3]. The act of 
cybersquatting is done merely to encash a huge sum of amount from the lawful owner of the trade name.

There are various Types of Cyber squatting like

\section{Typosquatting}

'URL hijacking', 'a sting site', and 'a fake URL' are usually referred to as typosquatting. Typically typosquaters rely on the mistakes done by internet users when tying a web address into a web browser and also exploit visual, hardware and sound similarities of trademark that can confuse an internet user. A fake website may also get created creating similar color scheme logos etc. Thus such websites are used by them to compel the real to buy it, generating more traffic and spreading malware.

\section{Identity Theft}

Usually it happens that the legitimate owners do forget to renew their domain or unintentionally failed to renew it in which case the cybersquatter may purchase the said domain name. They usually have software which allows them to monitor the expiry dates of targeted domain names. By this they can mislead users as to be owner of previous domain names.

\section{Name Jacking}

Usually the target people of this jackers are celebrities or famous personalities. It refers to the registration of domain name associated with such public figure. They benefit from the traffic related to these individuals. In the United States such personalities are given trademark protection for their name. Such association or name can attract a lot of traffic.

\section{Reverse Cyber squatting}

When an attempt is made to secure a domain name of a legitimate owner it refers to as a reverse cybersquatting. It involves intimidation and pressure on the legitimate owner to transfer such ownership to the organization or person which owns a registered trademark reflected in the domain name. [4]

\section{Targets of Cybersquatting}

As discussed earlier, cybersquatting involves buying or registering a domain name similar to that of a legitimate popular or successful one. The targets of such squatters are Company Names, Movie Titles, Products, Trademarks, and to encash a huge premium.

\section{Prevention of Cybersquatting}

Disputes pertaining to domain names of any nature are resolved in the absence of any particular law in that regard under Uniform Dispute Resolution Mechanism. As the domain name registrants have agreed to it. Through its arbitration and mediation centre the World Intellectual Property Organization has been backing such dispute resolution mechanism. The three measures that can be used to prevent cybersquatting are:-

The domain name must match with that of the company name instead of any generic random name.

Some countries have restricted registrants to have multiple domain names.

In United States for the prevention of and exclusively dealing with this regard a special legislation has been enacted. That is the Anti Cyber Piracy Act also known as
Anti Cyber Squatting Act. The act defines the rights on domain names. [5]

\section{RESULTS AND DISCUSSION}

The domain names or cybersquatting have not been defined or covered under any Indian specific enactments. The Indian courts have applied the Trade Marks law 1999 for such cases. Like many other similar cases under the Trade Marks Act 1999 two remedies are used for cybersquatting-

\section{Remedy of Infringement}

To avail the remedy of Infringement the trade mark needs to be a registered one. When the trademark used causes confusion or is similar to or deceptive of a trademark an infringement occurs.

\section{Remedy of Passing off.}

\section{PASSSING Off}

Lord Diplock identified five features that must be present in order to establish a valid cause of action for passing off in Erven Warnink v Townend (the 'Advocaat' case)[6]. These were:

1) ' a misrepresentation;

2) made by a trader in the course of trade;

3) to prospective customers of his or ultimate consumers of goods or services supplied by him;

4) which is calculated to injure the business or goodwill of another trader (in the sense that this is a reasonably foreseeable consequence); and

5) which causes actual damage to a business or goodwill of the trader by whom the action is brought or (in a quia timet action) will probably do so.[7]

In Tata Sons Limited and Anr Vs fashion ID Limited [8] it was held that "The use of the same or similar domain name may lead to a diversion of users which could result from such users mistakenly accessing one domain name instead of another. This may occur in e-commerce with its rapid progress and instant (and the erotically limitless) accessibility to users and potential customers and particularly so in areas of specific overlap. Ordinary consumers/users seeking to locate the functions available under one domain name may be confused if they accidentally arrived at a different but similar web site which offers no such services. Such users could well conclude that the first domain name owner had mis-represented its goods or services through its promotional activities and the first domain owner would thereby lose their customer. It is apparent therefore that a domain name may have all the characteristics of a trademark and could found an action for passing off"

In Dr Reddy's Laboratories Limited Vs Manu Kosuri and Anr[9] it was held that "It is a settled legal position that when a defendant does business under a name which is sufficiently close to the name under which the plaintiff is trading and that name has acquired a reputation the public at large is likely to be misled that the defendant's business is the business of the plaintiff or is a branch or department of 
the plaintiff, the defendant is liable for an action in passing off and it is always not necessary that there must be in existence goods of the plaintiff with which the defendant seeks to confuse his own domain name passing off may occur in cases where the plaintiffs do not in fact deal with the offending goods. When the plaintiffs and defendants are engaged in common or overlapping fields of activity, the competition would take place and there is grave and immense possibility for confusion and deception. The domain name serve same function as the trademark and is not a mere address or like finding number of the Internet and, Therefore, plaintiff is entitled to equal protection as trade mark. The domain name is more than a mere Internet address for it also identifies the Internet site to those who reach it. In an Internet service, a particular Internet site could be reached by anyone anywhere in the world who proposes to visit the said Internet site. In a matter where services rendered through the domain name in the Internet, a very alert vigil is necessary and a strict view needs to be taken for its easy access and reach by anyone from any corner of the world. The trademarks/domain name 'DR. REDDY'S' of the plaintiff and 'drreddyslab.com' of the defendants are almost similar except for use of the suffix 'lab.com' in the defendants domain use. The degree of the similarity of the marks usually is vitally important and significant in an action for passing off as in such a case, there is every possibility and likelihood of confusion and deception being caused. Considering both the domains' name, it is clear that two names being almost identical or similar in nature, there is every possibility of an Internet user being confused and deceived in believing that both the domain names belong to plaintiff although the two domain names belong to two different concerns".

Though in India there is no specific law dealing with cybersquatting and the typical mentality of people to avoid litigation process as it being time consuming, the legitimate owners prefer to shell out money to buy the domain name.

\section{CONCLUSION}

Cybersquatting is the real menace to the society. Though the domain names are there for the convenience and growth of the business never the less it has been misused by the fraudulent people. The world has realized the need to have an enactment just like the United States for dealing with it. In India the courts rely mostly on the IT Act 2000, Trade Marks Law 1999 and provisions of The Indian Penal Code. It is high time now for the India to have an enactment for Cybersquatting and other cyber menace and domain name protection.

\section{REFERENCES}

1. Rodney D. Ryder- "Guide to Cvber Laws (Information Technology Act. 2000. E-commerce. Data Protection \& the Internet" p. 149 (2001, 1st Edition).

2. AIR 2002 Del 243.

3. R.P. Kataria, S.K.P.Srinivas," Cyber Crimes Law Practice and Procedure", Orient Publishing Company2013, pp.350.

4. Dr. Daniel Dimov, Rasa Juzenaite, "Latest Trends in Cybersquatting”,Posted In Data Theft \& Financial Fraud On January 11, 2017. https://resources.infosecinstitute.com/latesttrends-in-cybersquatting/\#gref.
5. R.P. Kataria, S.K.P.Srinivas," Cyber Crimes Law Practice and Procedure", Orient Publishing Company2013, pp.351.

6. Ervin Warnink v Townend [1979] A.C. 731.

7. Ibid ., 93 .

8. (2005) 140 PLR 12

9. 2001 (58) DRJ241

10. Sarda, M., Deshpande, B., Dharm, J., Dhere, V., Different aspects of environmental laws, International Journal of Recent Technology and Engineering, 2019

11. Sarda, M., Deshpande, B., Deo, S., Karanjkar, A comparative study on Maslow's theory and Indian Ashrama system, International Journal of Innovative Technology and Exploring Engineering, 2018

12. Sarda, M., Deshpande, B., Shringarpure, S., Smart city - Use of technology and the needed labor reforms, International Journal of Innovative Technology and Exploring Engineering, 2018 